\title{
Soil Degradation-Induced Decline in Productivity of Sub-Saharan African Soils: The Prospects of Looking Downwards the Lowlands with the Sawah Ecotechnology
}

\author{
Sunday E. Obalum, ${ }^{1,2}$ Mohammed M. Buri, ${ }^{3}$ John C. Nwite, ${ }^{4}$ Hermansah, ${ }^{5}$ \\ Yoshinori Watanabe, ${ }^{1}$ Charles A. Igwe, ${ }^{1,2}$ and Toshiyuki Wakatsuki ${ }^{1}$ \\ ${ }^{1}$ School of Agriculture, Kinki University, Nara 631-8505, Japan \\ ${ }^{2}$ Department of Soil Science, University of Nigeria, Nsukka 410001, Nigeria \\ ${ }^{3}$ CSIR-Soil Research Institute, Academy Post Office, Kwadaso, Kumasi, Ghana \\ ${ }^{4}$ Department of Crop Production Technology, Federal College of Agriculture, P.M.B. 7008, Ishiagu, Nigeria \\ ${ }^{5}$ Department of Soil Science, Faculty of Agriculture, Andalas University, Limau Manis, Padang 25163, Indonesia \\ Correspondence should be addressed to Sunday E. Obalum, ijewelle@yahoo.com
}

Received 4 November 2011; Revised 13 January 2012; Accepted 16 January 2012

Academic Editor: Rosario García Moreno

Copyright ( $) 2012$ Sunday E. Obalum et al. This is an open access article distributed under the Creative Commons Attribution License, which permits unrestricted use, distribution, and reproduction in any medium, provided the original work is properly cited.

The paper provides an insight into the problem of land degradation in Sub-Saharan Africa, with emphasis on soil erosion and its effect on soil quality and productivity, and proposes a lowland-based rice-production technology for coping with the situation. Crop yields are, in addition to the degree of past and current erosion, determined by a number of interacting variables. This, coupled with the generally weak database on erosion-induced losses in crop yield in spite of the region's high vulnerability to erosion, makes it difficult to attain a reliable inference on the cause-effect relationship between soil loss and productivity. Available data suggest, however, that the region is at risk of not meeting up with the challenges of agriculture in this 21 st century. Based on the few studies reviewed, methodology appears to have an overwhelming influence on the erosion-productivity response, whereas issues bordering on physical environment and soil affect the shape of the response curve. We argue that the sawah ecotechnology has the potential of countering the negative agronomic and environmental impacts of land degradation in Sub-Saharan Africa. This is a farmer-oriented, low-cost system of managing soil, water, and nutrient resources for enhancing lowland rice productivity and realizing Green Revolution in the region.

\section{Introduction}

Ever since mankind started agriculture, soil erosion has been the single largest threat to soil productivity and has remained so till date [1]. This is so because removal of the topsoil by any means has, through research and historical evidence, been severally shown to have many deleterious effects on the productive capacity of the soil as well as on ecological wellbeing. Doran and Parkin [2] captioned the impact of soil erosion in their popular maxim that "the thin layer of soil covering the earth's surface represents the difference between survival and extinction for most terrestrial life." Although fertile topsoils could be lost when scraped by heavy machineries [3], the key avenues of topsoil loss include water erosion and wind erosion. Sometimes erosion can be such gradual for so long a time as to elude detection in one's lifetime, thus making its adverse effects hard to detect. Eswaran et al. [4] propose an annual loss of 75 billion tons of soil on a global basis which costs the world about US $\$ 400$ billion per year. A review of the global agronomic impact of soil erosion identifies two severity groups of continents and reveals that Africa belongs to the more vulnerable group [5].

Soil erosion by water seems to be the greatest factor limiting soil productivity and impeding agricultural enterprise in the entire humid tropical region [6]. This is evident in many regions of Africa [7], mainly in the humid and 
subhumid zones of Sub-Saharan Africa (SSA) where population pressure and deforestation exacerbate the situation and the rains come as torrential downpours, with the annual soil loss put at over 50 tons ha ${ }^{-1}$ [8]. In SSA, the problem is not limited to water erosion as wind erosion prevails mainly in the semiarid and arid zones. For instance, soil loss to wind erosion of $58-80$ tons ha $^{-1}$ has recently been reported from the West African Sahel [9]. Both forms of erosion can thus aptly define land degradation in the region. Soil erosion selectively detaches the colloidal fractions of soils and carts them away in runoff $[10,11]$. These soil colloidal fractions (clay and humus) are needed for soil fertility, aggregation, structural stability, and favourable pore size distribution. The concentration of humus is usually higher in topsoils while that of clay is usually higher in subsoils due to illuviation, and this is mostly true in Ultisols that are widespread in Africa. This implies that humus, which has much greater capacity to hold water and nutrient ions compared to clay, its inorganic counterpart [12], is the more easily eroded.

In spite of the fact that the problem of land degradation is particularly severe in SSA, only little reliable data were available by the end of the 20th century both on its extent [ 8 , 13] and on the cause-effect relationship between soil erosion and soil productivity $[4,14]$. Thereafter, no significant research progress has been made to beef up the data in the region. We review in this paper the little available data, with a focus on soil properties modified by erosion and the extent of erosion-induced decline in the yield of commonly grown crops, which is viewed as a proxy for soil productivity. The survey highlights the enormous rate of soil erosion and the attendant decline in the productivity of agricultural soils in SSA. It is therefore unsurprising that, in the face of the advances so far made in biotechnology, agricultural productivity in SSA stagnates and remains perennially low as evident in hunger and poverty levels in the entire region $[15,16]$.

All the adverse impacts on agronomic productivity and environmental quality are respectively due to a decline in land quality and deposition of sediments and have been designated on-site effect and off-site effect, respectively [4, 11]. It is widely believed that erosion-induced deposition of sediments occurs in response to topographic gradients and that, since water does not climb hills in agricultural watersheds, the process is hardly reversible. With this in view, we make a case for tackling the agroecological problem of soil erosion in the diverse watersheds of SSA offsite rather than onsite. This is a case for the sawah ecotechnology, an Asiantype system of rice (Oryza sativa L.) production that has been adapted in the abundant lowlands in the region. The system can compensate for the loss of upland soil productivity while counteracting the environmental degradation due to soil erosion. It is viewed as the promising option to boosting rice production on a sustainable basis for the realization of the much-awaited Green Revolution in SSA.

\section{Soil Loss and Crops Yields in Sub-Saharan Africa: A Survey of the Literature}

2.1. Indices of Soil Productivity Affected by Soil Loss. Soil productivity is the capacity of a soil to produce a certain yield of crops or other plants under a defined set of management practices [17]. Thus comparison of soil productivity losses to erosion should be done for similar soil and crop management scenarios. Soil productivity entails striking a balance among soil "physical," "chemical," and "biological" fertilities, as none is of much value without others. All these soil properties are affected by topsoil removal; crop yields are affected through the resulting changes in these soil properties. Some of the ways by which soil erosion reduces its productivity include removal of plant nutrients in the eroded sediments, exposure of root-toxic and poorly aerated subsoils, $\mathrm{P}$ tie-up in illuviated clay which makes it apparently the most deficient nutrient in eroded soils, soil structure deformation leading to surface sealing and crusting which reduce seedling emergence and infiltration, and nonuniform removal of soil within a field which complicates the task of managing the soil to maximize production $[14,18]$.

Soil erosion or simulation of topsoil loss has been severally reported to adversely influence such soil physical properties as root zone depth, gravel content, particle size distribution, strength, bulk density, porosity, aggregate stability, moisture retention capacity, moisture characteristics, saturated hydraulic conductivities, and infiltration rates in SSA [3, 19-29]. The presence of organic matter in the surface soil generally promotes aggregation and may engender a situation where moisture-retaining pores are preponderant in soil. Soil erosion reduces its productivity primarily through the loss of plant available water capacity. Three months after the artificial removal of the top $(5 \mathrm{~cm})$ soil at three locations in southern Nigeria, Mbagwu et al. [23] observed reductions in moisture retention capacity and saturated hydraulic conductivities of the exposed soil layer, which were greater in Ultisols than in Alfisols. Mbagwu and Lal [30] later reported that limited moisture more than increased compaction caused greater reduction in root growth and dry matter of maize (Zea mays L.) and cowpea (Vigna unguiculata L.) in those locations.

Soil chemical properties that are mostly adversely influenced by erosion or topsoil removal in SSA include $\mathrm{pH}$, organic matter content, total $\mathrm{N}$, available $\mathrm{P}$, exchangeable bases, and cation exchange capacity [3, 21, 24-26, 28, 29, 31]. In an Alfisol in southwestern Nigeria, Lal [32] reported that the enrichment ratio (ER, the concentration of plant nutrients in eroded soil materials to that in residual soil) was 2.4 for organic matter, 1.6 for total N, 5.8 for available P, 1.7 for exchangeable $\mathrm{K}, 1.5$ for exchangeable $\mathrm{Ca}$, and 1.2 for exchangeable Mg. For another Alfisol in Central Kenya recording an annual soil loss of above 60 tons ha $^{-1}$, the corresponding values of the ER were 2.1, 1.2, 3.2, 1.5, 1.2, and 1.0 , respectively [33].

2.2. The Nature and Magnitude of Erosion-Induced Yield Decline in Sub-Saharan Africa. Although topsoil loss generally has adverse effects on productivity of soils, there can sometimes be an artifact in which case the loss improves soil productivity or at least does not affect it adversely [34]. This is often as a result of exposure of the surface of a previously buried productive soil following erosion [35]. 
Such a situation can be found in some deep Andisols and Inceptisols [26], but hardly occurs in the relatively shallow Alfisols, Ultisols, and Oxisols predominant in the tropics, in which nutrients are concentrated in the surface layer [36]. We are thus primarily concerned with the negative impact of soil erosion on soil productivity, which is the more commonly reported observation in SSA. The adverse impacts of soil erosion on agronomic productivity might be of short term or long term (Figure 1).

Virtually all the short-term effects stem from a reduction in the thickness of surface layers and a selective reduction in the components of such layers that are essential for crop production. Long-term effects stem from the ensuing progressive reduction in the rooting zone depth.

As a first-hand appreciation of the peculiarity of erosioninduced degradation in SSA, no portion of only about 3\% of the global land surface considered as prime or class 1 falls into the tropical region [4], to which belongs SSA and which accounts for about $39 \%$ of the world's land surface [37]. In the humid and subhumid zones of West Africa, deforestation proceeds at a rate of about 4 million ha per year, with deforestation to reforestation ratio of $30: 1$ on the average [8]. However, information on the extent and severity of natural and anthropogenic soil erosion and on the quantitative cause-effect relationships between soil loss and productivity of agricultural lands prone to erosion in SSA is generally lacking or, where available, is weak, subjective, and unreliable. This situation has been attributed to the difficulty in conducting the long-term, concentrated interdisciplinary research (including financial/time constraints) which is needed to overcome the complexity posed by annual and seasonal variations in number and magnitude of erosion, the multifactorial nature of yield factors, as well as the belief that inorganic fertilizers are all-ameliorating $[4,14,19,35,38]$. However, available data to date suggest a severity of erosion hazards in many agroecological zones of the SSA, with cases of advanced gullies in some of the zones (Figure 2) [39].

Dregne [7] reported that irreversible soil productivity losses from water erosion appeared to be serious on a national scale in Algeria, Morocco, and Tunisia in North Africa; in Ethiopia, Kenya, and Uganda in East Africa; in Nigeria and northern Ghana in West Africa; and in Lesotho, Swaziland, and Zimbabwe in southern Africa. He observed as much as 50\% productivity loss to wind erosion in part of Tunisia, and delineated areas in Africa where about $20 \%$ permanent reduction on crop productivity have resulted from human-induced water and wind erosion. Lal [14] estimated that past erosion in Africa has caused yield reduction of $2-40 \%$, and that if present trend continues, the yield reduction by 2020 may be $16.5 \%$.

\subsection{Selected Cases of Assessed Impact of Soil Loss in Sub-Saharan Africa}

2.3.1. Desurfacing Experiments. In spite of the weak points of desurfacing experiments, most studies on erosion-induced decline in soil productivity in the tropics were done on artificially-desurfaced soils in order to close the information gap on soil loss and crop productivity relationship in the region [24]. The method is favoured in this region also because of the difficulty of separating the effect of past erosion from that of the present erosion vis-à-vis the rather few examples on the assessment of the impact of current rate of erosion on crop yield [11]. Selected trials based on topsoil desurfacing in SSA are summarized in Table 1. As a further hint to the data shown, it was reported in one of these trials that the relationship between the grain yield of maize, $Y_{a}$ and $Y_{b}$ (tons $\mathrm{ha}^{-1}$ ) in the first and second year respectively, and the depth of topsoil desurfaced, $x(\mathrm{~cm})$, was of the exponential form [27]:

$$
\begin{array}{ll}
Y_{a}=3.2761 e^{-0.1621 x} & \left(R^{2}=0.998\right), \\
Y_{b}=1.6116 e^{-0.1489 x} & \left(R^{2}=0.985\right) .
\end{array}
$$

2.3.2. Natural Soil Erosion. Studies on natural soil erosion are relatively few in SSA because such trials are conducted on runoff plots which are limited in number in the region. Moreover, such studies do not give rapid results since erosion is a gradual process such that noticeable differences in crop yield may take a long time to be established. The attraction for results emanating from this method, however, is that they reflect what happens in the field under natural conditions and so give the most realistic and reliable results. Few studies based on natural soil erosion are summarized in Table 2.

Lal [21] studied the effect of accumulative soil erosion for a 5-year period on the yields of maize and cowpea in Alfisols and reported that the reductions in their yields were, respectively, 9.0 and $0.7 \mathrm{~kg}$ ton $^{-1}$ of soil loss. He also obtained the following linear relationships between yield, $Y$, in tons ha ${ }^{-1}$ and soil erosion, $E$, in tons ha ${ }^{-1}$ :

$$
\begin{aligned}
Y_{\text {maize }} & =5.95-0.009 E, \quad r=-0.87^{*}, \\
Y_{\text {cowpea }} & =0.407-0.0007 E, \quad r=-0.66^{*} .
\end{aligned}
$$

It was reported from Tanzania that reductions in maize yields due to severe past erosion of soils ranged from 15 to $48 \%$ [11]. From runoff plots located on a sandy loam Ultisol in Kumasi, Ghana, subjected to four different tillage practices, Adama and Quansah [41] reported that the grain yield of maize, $Y$, in $\mathrm{kg} \mathrm{ha}^{-1}$ in the major season and cumulative soil loss, $E$, in tons ha ${ }^{-1}$ in the same season plus that in the previous year were related thus:

$$
Y=2686-13.92 E, \quad r=-0.94^{*} .
$$

2.3.3. Greenhouse Experiments. Under greenhouse conditions, the yield of maize was found to be $20-50 \%$ (with a mean of $40 \%$ ) higher on surface soil than on subsurface soil, the latter of which showed to be deficient in $\mathrm{N}$ and $\mathrm{P}$ [42]. Mbagwu [24] reported that without any amendment, maize and cowpea yields were, respectively, reduced by 58 and $19 \%$ on soils from runoff plots established 12 years earlier on an Ultisol in southeastern Nigeria, with a soil loss rate of 55 tons $\mathrm{yr}^{-1}$. With the addition of brewers' grains to the eroded soil under both crops, however, maize and cowpea showed lower yield reductions of 22 and 9\%, respectively. 


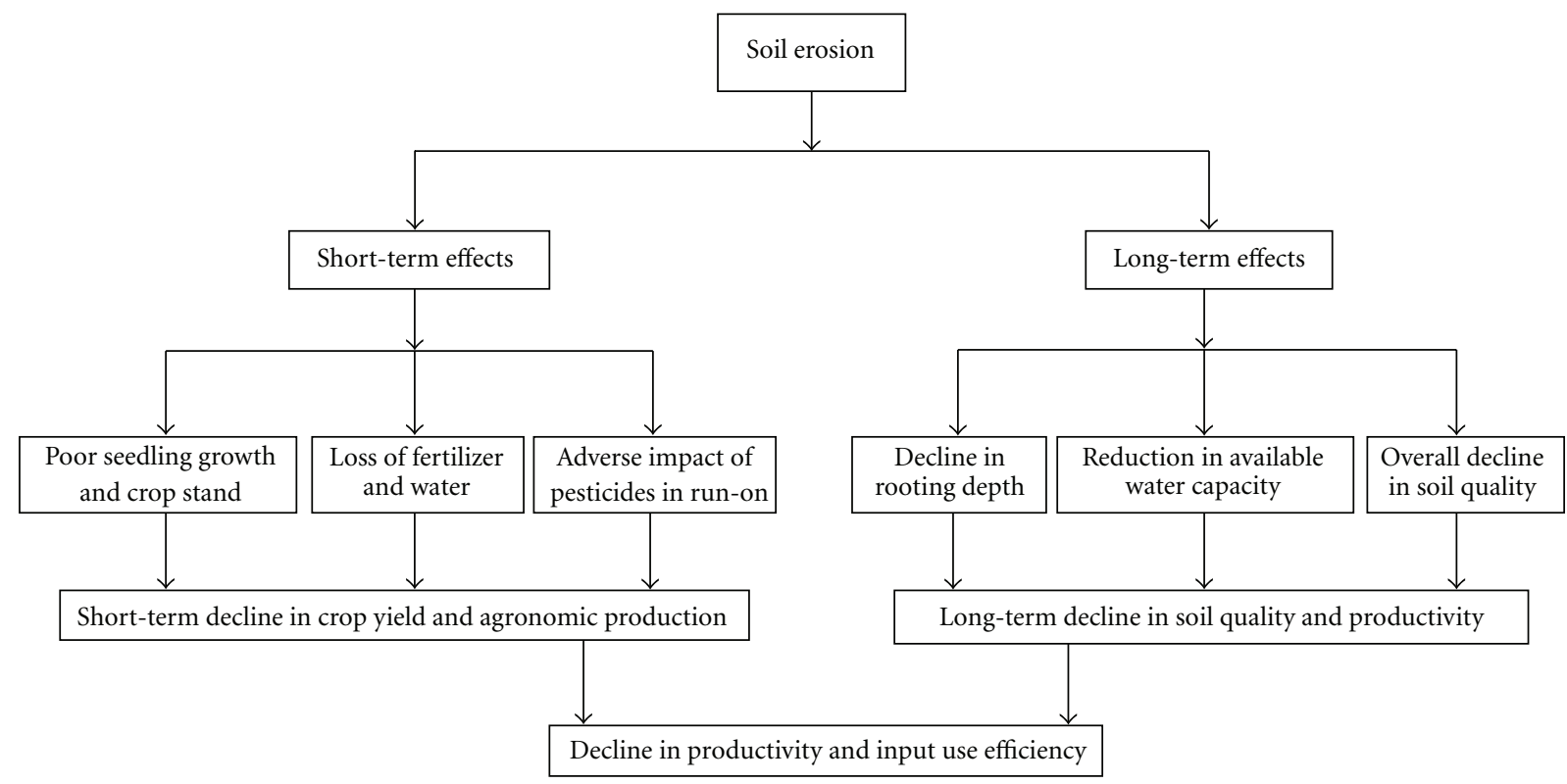

FIGURE 1: On-site effects of soil erosion on productivity decline (source: Lal et al. [11]).

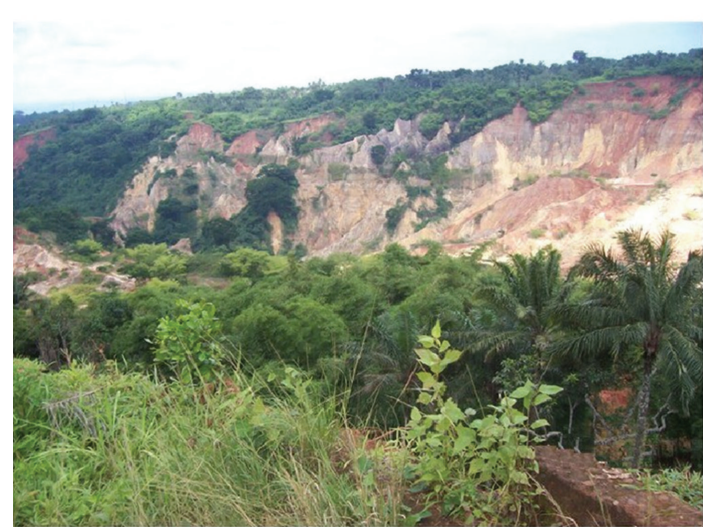

Figure 2: A gullied farmland in southeastern Nigeria, after Igwe [39].

In a separate study, Mbagwu [36] reported that the topsoils outyielded the subsoils by a range of $18-40 \%$ on two Alfisols, two Ultisols, and one Inceptisol in southern Nigeria.

From the information for the desurfacing studies (Table 1), there appears to be a convex relationship between soil loss and productivity, that is, increasing productivity loss with increasing soil loss. The data also reveal that yield losses to soil erosion are more severe on Ultisols than Alfisols, thus implying that Ultisols have lower $T$ values than Alfisols. This is attributed to the generally lower inherent fertility status of Ultisols than Alfisols [12, 40]. Yield reductions are also consistently lower for cowpea than for maize; irrespective of method of achieving soil loss, of soil order, and of location. This has been attributed to the ability of cowpea to nodulate, which maize could not do [40]. Notably, as the erosion severity increases, the percent reduction in the yield of cassava (Manihot esculentum C.) increases, which is not the case with the other crops. The explanation lies in the fact that cassava is a deep-feeder crop, unlike cereals and legumes which are relatively shallow feeders.

Furthermore, the comparison of the data in Table 1 with those in Table 2 reveals that yield reduction per centimetre of soil loss is always higher on naturally eroded soils than in soils from where equivalent soil depths have been desurfaced. This could be due partly to the fact that rains compact the soil whereas desurfacing does not. On two adjacent plots, Lal [14] reported that the decline in maize yield by natural erosion was about 16 times more than that by desurfacing. However, the topsoil is never uniformly removed in one growing season by natural erosion as does desurfacing. Therefore, within the same time scale, the sudden and total disappearance of topsoil due to desurfacing would be expected to result in much stronger changes in soil properties than with natural soil erosion, such that the negative effect of erosion on soil productivity may be exaggerated [43]. And that is the reason why den Biggelaar et al. [5] view studies on present erosion as mimicking inappropriate soil management practices and their adverse effects. The data in Tables 1 and 2 thus support the view that erosionproductivity relationships generated by different methods are hard to compare $[4,43]$.

\section{Sustaining Soil Productivity against Land Degradation in Sub-Saharan Africa}

Using the study by Oyedele and Aina [25] in southwestern Nigeria as a reference point, soil chemical properties can account for over $75 \%$ of the variation in the yield of cereals from eroded soils in SSA. Thus, erosion-induced shortterm decline in productivity is more easily compensated by 
TABLE 1: Erosion-productivity relationship for soils of Sub-Saharan Africa (desurfacing experiments).

\begin{tabular}{|c|c|c|c|c|c|}
\hline Soil loss $(\mathrm{cm})$ & Yield reduction $(\%)$ & Soil order & Climate/location & Country & Source \\
\hline \multicolumn{6}{|c|}{ Maize (Zea mays L.) as a test crop } \\
\hline $2.5,5,7.5,10,12.5$ & $23,38,49,53,56$ & Alfisol & Subhumid Ibadan & Nigeria & [19] \\
\hline $5,10,20$ & $72.5,82.6,99.5$ & Alfisol & Subhumid Ilora & Nigeria & {$[40]$} \\
\hline $5,10,20$ & $30.5,73.6,93.5$ & Alfisol & Subhumid Ikenne & Nigeria & {$[40]$} \\
\hline $5,10,20$ & $95.4,95.4,100$ & Ultisol & Humid Onne & Nigeria & {$[40]$} \\
\hline 5 & 54.9 & Alfisol & Subhumid Ilora & Nigeria & {$[36]$} \\
\hline 5 & 30 & Alfisol & Subhumid Ikenne & Nigeria & {$[36]$} \\
\hline 5 & 15 & Inceptisol & Subhumid Nsukka & Nigeria & {$[36]$} \\
\hline 5 & 69.7 & Ultisol & Humid Onne & Nigeria & {$[36]$} \\
\hline 5 & 64.2 & Ultisol & Subhumid Nsukka & Nigeria & {$[36]$} \\
\hline 10,20 & $39.2,81.7$ & Alfisol & Subhumid Ibadan & Nigeria & {$[14]$} \\
\hline $2.5,7.5$ & $50, \gg 100$ & Ultisol & Humid Douala & Cameroon & {$[14]$} \\
\hline $5,10,20$ & $47,48,63$ & Lateritic Alfisol & Semiarid Ouagadougou & Burkina Faso & {$[14]$} \\
\hline 3,6 & 23,55 & Ultisol & Subhumid Nsukka (1) & Nigeria & {$[3]$} \\
\hline 3,6 & 50,95 & Ultisol & Subhumid Nsukka (2) & Nigeria & {$[3]$} \\
\hline $5,10,15,20$ & $56.0,82.5,90.0,95.5$ & Oxisol & Subhumid Ile-Ife & Nigeria & {$[27]$} \\
\hline 15,25 & 17, 67 (upper slope); 65, 76 (lower slope) & Gravelly Alfisol & Subhumid Ibadan & Nigeria & [29] \\
\hline \multicolumn{6}{|c|}{ Cowpea (Vigna unguiculata L.) as a test crop } \\
\hline $5,10,20$ & $42.6,33.1,80.5$ & Alfisol & Subhumid Ilora & Nigeria & {$[40]$} \\
\hline $5,10,20$ & $1.5,59.1,65.1$ & Alfisol & Subhumid Ikenne & Nigeria & {$[40]$} \\
\hline $5,10,20$ & $62.0,70.6,68.3$ & Ultisol & Humid Onne & Nigeria & {$[40]$} \\
\hline \multicolumn{6}{|c|}{ Cassava (Manihot esculentus C.) as a test crop } \\
\hline 10,20 & $35.7,53.7$ & Alfisol & Subhumid Ibadan & Nigeria & {$[40]$} \\
\hline
\end{tabular}

Quantification was achieved where both the depth of soil loss and the yield reduction were given by the authors or could be calculated from the information they presented.

TABLE 2: Erosion-productivity relationship for soils of Sub-Saharan Africa (natural erosion).

\begin{tabular}{lcccc}
\hline Soil loss $(\mathrm{cm})$ & Yield reduction $(\%)$ & Soil order & Climate/location & Country \\
\hline Maize $($ Zea mays L.) as a test crop & & & Source \\
0.0024 & 26.9 & Alfisol & Semiarid Harare & Zimbabwe \\
0.0080 & 0.1513 & Alfisol & Subhumid Ibadan & Nigeria \\
0.0080 & 0.1720 & Alfisol & Subhumid Ibadan & Nigeria \\
Pearl millet (Pennisetum americanum L.) as a test crop & & & {$[21]$} \\
0.0928 & 51.6 & Aridisol & Semiarid Niangoloko & Burkina Faso \\
\hline
\end{tabular}

All soil erosion rates were converted to equivalent depths of soil loss, assuming a bulk density of $1.25 \mathrm{mg} \mathrm{m}^{-3}$.

inorganic and/or organic fertilization and supplemental irrigation, as opposed to long-term decline in productivity [11]. However, the efficiency of inorganic fertilizer in an eroded soil where the physical properties are degraded alongside chemical nutrients depletion depends, to a large extent, on the dynamic relationship between the level of harm done to the soil's physical condition and the level of progress made in the difficult task of improving it [35, 44, 45]. Such a situation needs a combination of carefully selected, suitable management practices depending on the shape of the yield reduction function. In Nigeria, for instance, research evidence from eroded Alfisols suggests that, rather than inorganic fertilization, application of poultry manure and fallowing to various grass and leguminous species for two years could improve the soil physicochemical properties and productivity $[29,46]$.

The situation in SSA calls for more sustainable farming systems and underscores the need to look beyond the use of inorganic fertilizers as a means of restoring the productivity of naturally eroded soils in the region. Except in the case of gullies where urgent intervention may be needed, incorporation of cover cropping into our agronomic systems can help to conserve "yet-to-be-degraded" soils against degradation while forestalling further erosion from already "degraded" upland soils [33]. Such a soil management practice allows eroded soils the chance to restore the loss in productivity at a rate commensurate with their resilience. For some time now, however, the question has been on 
how to accommodate better the problem of soil erosion in SSA as part of livelihood strategies [13]. We propose in this paper that it would be more profitable to focus greater efforts on developing our huge lowland resources with the sawah ecotechnology. The sawah system is based on the concept of watershed development and, so, is an adaptation of the Japanese "Satoyama" system to African environments. Figure 3 is an example of African "Satoyama" concept, which is a watershed agroforestry applicable to cocoa belt region in West Africa.

Sawah refers to a lowland field that is demarcated using earthen bunds, puddled and leveled using a handoperated power tiller, transplanted to a high-yielding rice variety in rows, and kept under regulated submergence throughout the growing season (Figure 4). Thus unlike the traditional lowland rice field that is a diverse and mixedup environment, the lowland sawah system is a diverse and intensified rice-growing environment that is characterized by well-designed and well-demarcated field condition with clearly defined management of soil, water, and nutrient resources. The term sawah is of Malayo-Indonesian origin but has been adopted in SSA as corresponding to paddy fields in Asia. The adoption became necessary in order to differentiate the technology from unprocessed rice grain, upland rice field, or traditional lowland rice field (all of which are regularly referred to as paddy in SSA). It is hoped that the clearing of these terminological uncertainties would foster the sharing of ideas and strategies among all the stakeholders in rice production [16].

\section{Why the Lowland Sawah Ecotechnology?}

There is no gainsaying that food production in SSA needs to transit for its present level to the next level in terms of simultaneously increasing the output and conserving the natural environments. One of the ways of achieving this task is to work towards modifying the offsite effect of erosion, such that rather than compromising environmental quality, eroded sediments that eventually get deposited in the lowlands can be harnessed to contribute to agricultural production and environmental quality using such an appropriate technology as the lowland sawah systems. Because of the significant contribution of this sediment deposition process (otherwise known as geologic fertilization) to the fertility of lowland soils of SSA [48], the case for the sawah ecotechnology is clearly that of diverting attention from onsite to offsite as a means of coping with the problem of soil erosion.

In the first place, out of the about 2.4 billion ha of land in SSA, lowlands comprise about 250 million ha [49]. This implies that lowlands occupy above $10 \%$ of the region's land mass. The majority of the lowlands have huge potential for increasing agricultural production in SSA, yet many of them remain unexploited and most others grossly underutilized [50]. In his essay, "African Green Revolution needn't be a mirage," Ejeta [15] noted that in Africa where the culture of looking up to science for solutions to local problems is not well established, the people can realize Green Revolution with locally developed and locally relevant technologies. We can thus rhetorically "look downwards to a lowland technology" as an alternative to our quest for a sustainable agricultural production system in Africa. The people are increasingly conscious of this option. Consequently, gone are the days before the mid 1990s when there was a greater emphasis on growing rice in upland agricultural soils than in the lowland ecosystems under rainfed conditions $[16,51]$. In West Africa that leads the rest of SSA in rice production, for instance, the ratio of uplands to lowlands in terms of area under rice is $10.00: 6.13$, and this ratio is rapidly decreasing [52].

Similar to their attitude of not looking up to science for solutions to local problems, African farmers tend to be alienated from any science-oriented agricultural production system that is not rooted in their farming culture and to which their indigenous knowledge does not make any contribution. To buttress this point, the peoples' shift of preference from upland to lowland farming has been identified as one of the reasons for the failure of agroforestry to achieve the success expected of it at the onset [51]. This may not be the case with the sawah ecotechnology in the lowlands where rice has been a traditional crop in Africa. Instead, the farmers in the region view the technology as that which is taking them from what they already know to how they can do it better. Apart from being agroecosystems that the farmers are familiar with, lowlands denote agroecologies of low elevation and so mostly offer favourable hydrological conditions for the rice crop. Particularly in the Equatorial Forest and the Guinea Savanna Zones, precipitation and lateral groundwater flow from the adjacent uplands cause the lower footslopes and valley bottoms to be saturated or flooded for a certain period, thereby ensuring a potentially long cropping period that permits either double rice cropping or cultivation of vegetables and root crops after rice [49].

Moreover, sediments from such runoffs can engender favourable soil hydrophysical status for sawah-managed rice, and this is usually most evident in the extreme valley bottoms [53]. There is thus more to the aforementioned geological fertilization. Such a natural mechanism of replenishment of soil "physical" and "chemical" fertility can be imagined from Figure 3. The aspect of enriching sawah system with plant nutrients is particularly cherished because of the inherently low-fertility status of the lowland soils in SSA [54] vis-à-vis the relatively low level of fertilizer use by SSA farmers [55]. Owing to the topographic position of the lowlands and to the ecological engineering works that go with sawah systems design, erosion is reduced to almost zero in these ecologies with the sawah ecotechnology. This, among other benefits, assures that the topsoil that is characterized by low bulk density especially early in the season (due to the puddling exercise) is not washed away, thus sparing the nutrient-rich sediments transported from the uplands. The technology is therefore very effective for conserving soil, water, nutrients, and the overall environment.

An earlier proposal for rice farming in West Africa is that uplands should be cultivated with short-to-long fallow periods, whereas large inland valleys, coastal plains, 


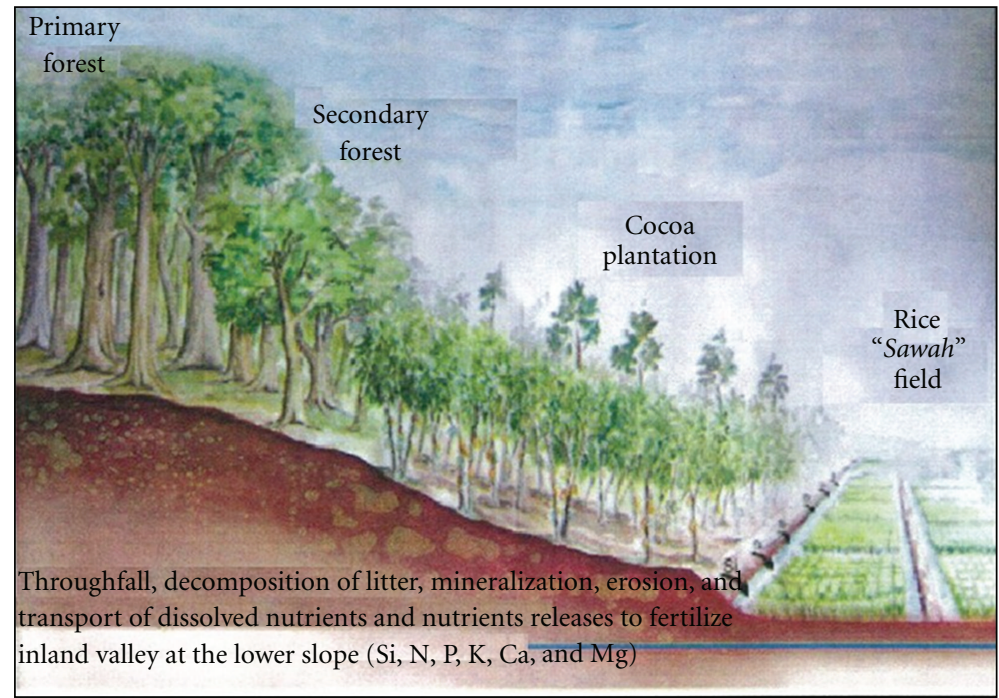

FIgure 3: A typical example of African SATO-YAMA Concept developed by the Forest Research Institute of Ghana, after Owusu-Sekyere et al. [47].

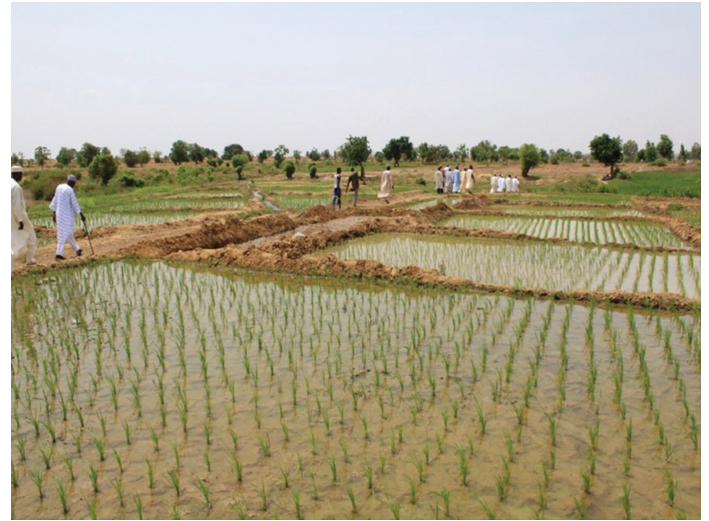

FIGURE 4: A newly developed sawah field located in an inland valley in Jega, Kebbi State of Nigeria.

and floodplains should be cultivated more intensively [49]. However, the existing research concept to improve natural resource management in SSA may not bring about the desired results among the lowland rice farmers, unless there is a clearly defined research concept to improve soil and water conditions of the lowlands. Application of the three core Green Revolution technologies (high-yielding varieties, inorganic fertilizers, and irrigation facilities) outside the sawah system can even degrade the environment, such as that emanating from inefficient fertilizer use under situations of poor water management prevailing in non-sawah rice fields [48]. At the moment, the sawah ecotechnology appears to bring to an end the search for a farming system that addresses this issue in the region. So, for the advocacy for increased fertilizer use in Africa [55] to suitably apply to lowlands, sawah systems must first be put in place. The farmers themselves now know that the high-yielding varieties respond well to fertilizers only when they are grown under favourable soil and water conditions [16]. The sawah ecotechnology is therefore the only rice-farming system in the lowlands that can permit the proposed intensive cultivation of these rice ecologies on a sustainable basis, that is, without compromising high yields and environmental quality [48].

The sawah ecotechnology in the lowlands has a lot of prospects for coping with land degradation and ensuring sustainable agricultural production in SSA. Our 15-year and continuing trials in Ghana and Nigeria have demonstrated that the sawah system is the prerequisite for successfully applying the other Green Revolution technologies to realize lowland rice potential in SSA. The technology is farmerfriendly because the farmer is empowered to have absolute control and management of water in his field, which enables them to enjoy a flexible - and hence convenient-time table for the farming season. We hypothesize that if the farmer is placed at the centre of the creation of lowland sawah systems, field water control can be more effective and the struggle for a sustainable rice production system and a rice Green Revolution in SSA can be won. This is our sawah hypothesis I.

Furthermore, a properly managed sawah system has the potential of providing ecosystem services. This is mainly through enhanced $\mathrm{C}$ sequestration in forests and soils and the associated alleviatory effect on global warming problems [50]. The sawah system also neutralizes the soil $\mathrm{pH}$ thereby enhancing the availability of $\mathrm{P}$ and micronutrients in the soil. Such a condition of favourable soil nutrient status encourages the proliferation of a myriad of mostly anaerobic and photosynthetic microbes which, through a microbial nanowire collaborative network, constitute strong mechanisms for biological $\mathrm{N}$ fixation. In Asia, this phenomenon can result in annual values ranging from 20 to $200 \mathrm{~kg} \mathrm{Nha}^{-1}$, depending on the biophysical and the ricegrowing environments [48]. The sawah system, thus, does not depend on only Azolla to sustain biological $\mathrm{N}$ in the soil. 
Other benefits of the sawah system include favourable soil redox processes and suppression of weed growth due mainly to both the submerged soil condition and good tillering.

Above all, the mean grain yield of upland rice in West Africa is about 0.9 tons ha ${ }^{-1}$ [49]. To show that such low yields relate largely to the growing ecology and farming system, some scientists recently reported that the mean grain yield of the new rice cultivar for Africa (NERICA) from three locations in southern Benin was only 1.14 tons ha ${ }^{-1}$, the fact that it was grown on previously fallowed uplands and with adequate fertilization notwithstanding [56]. On the other hand, rice grain yield under the sawah system ranges from 4.0 to 8.0 tons $\mathrm{ha}^{-1}$, depending on the rice variety grown, external input level, water management, and other agronomic and management practices [57, 58]. On the average, therefore, the data just stated represent roughly between 4 and 8 times lower grain yield of rice under the upland growing systems than under the novel lowland sawah systems.

However, considering the fact that the upland system involves fallow periods which are not necessary under the sawah system, the yield gap between the two systems widens. At least 10 ha of upland is taken to be an equivalent of 1 ha of lowland sawah in terms of yield in a growing season. This is our sawah hypothesis II. In other words, each hectare of lowland sawah field enables the conservation of at least 10 ha of forest area. Sawah fields can thus foster both increased food production and forest conservation, which in turn enhances the sustainability of intensive lowland sawah systems by way of enhanced water conservation and supply of fertile topsoils through the geological fertilization. All this points to the sustainable nature of sawah systems compared to the upland rice culture which is mostly characterized by slash and burn, thereby degrading further our agroecological systems and environments.

\section{Challenges of the Sawah Ecotechnology in Sub-Saharan Africa}

Lowlands are particularly vulnerable to climate and environmental changes. For instance, the rise in sea level associated with contemporary global warming would, by modifying the coastal environments, ultimately affect the hydrological conditions of the lowlands. Hence, the lowlands are occasionally subject to such natural disasters as flooding. Multidisciplinary research is thus needed to reinforce the lowland sawah ecotechnology against such disasters. Closely related to this in the SSA environments is the need to empirically devise a means of coping with the possible adverse effect of the destabilization of soil structure by puddling. Granted that erosion is not a problem in lowland sawah soils, puddled soils may behave differently in the event of flood disasters if the soil structure does not regenerate properly. The off-season structural status of puddled lowland soils can also influence the performance of any crop grown after rice, thus stressing the need for a research on postsawah crops that would maximize the use of the lowland soil resources in the region.
Furthermore, considering the importance of natural soil fertility replenishment as a way of minimizing inorganic fertilization and the associated reduction in economic returns, the extent of geological fertilization in different topographical and land-cover conditions needs to be quantified. Similarly, we only know of the extent of biological nitrogen fixation in Asian paddy fields, such is yet to be evaluated for the sawah systems in SSA with a different hydrophysical environment [50]. This is important, considering the low geological fertilization of the lowlands with respect to total $\mathrm{N}$ compared to available $\mathrm{P}[32,33]$. Finally, the sawah hypothesis II is yet to be validated in SSA environments. All this is needed to strengthen the case for the sawah systems as a means of simultaneously mitigating land degradation, ensuring sustainable rice production and promoting ecological wellbeing.

\section{Perspectives}

In most of the SSA, land degradation potentially undermines efforts towards sustainable agricultural production and so poses a major threat to the future of agriculture. Regrettably, available data to date on the quantitative relationship between soil loss and reductions in crop yield in the region are still fragmentary and grossly insufficient. The little available data, though characterized by a wide disparity, highlight the enormous loss of soil productivity to erosion in the region. The sawah ecotechnology for lowland rice production holds a lot of prospects. Although concentrated in the lowlands, well-managed sawah systems can help to conserve soil and water in the entire watershed. With the technology, SSA countries have the opportunity of achieving self-sufficiency in rice production while enhancing the quality of their environments. Although there are still areas needing long-term collaborative research in the adaptation of the sawah systems to SSA environments, we are so far convinced that proper application of the sawah ecotechnology at the rice farmer's field is a prerequisite for successfully applying other Green Revolution technologies.

\section{Acknowledgments}

The authors gratefully acknowledge the sponsorship of the Ministry of Education, Culture, Sports, Science and Technology (MEXT) of the Japanese Government through the Monbukagakusho Scholarship, the Japan Society for the Promotion of Science (JSPS), and New Sawah Project of the Kinki University of Japan.

\section{References}

[1] P. Sullivan, "Sustainable soil management: soil systems guide," Appropriate Technology Transfer for Rural Areas (ATTRA) Fayetteville AR 72702, National Center for Appropriate Technology (NCAT), 2004.

[2] J. W. Doran and T. B. Parkin, "Defining and assessing soil quality," in Defining Soil Quality for a Sustainable Environment, J. W. Doran et al., Ed., vol. 35, Soil Science Society of America Special Publication, Madison, Wis, USA, 1994. 
[3] O. E. Ngwu, J. S. C. Mbagwu, and M. E. Obi, "Effect of desurfacing on soil properties and maize yield-research note," Nigerian Journal of Soil Science, vol. 15, no. 2, pp. 148150, 2005.

[4] H. Eswaran, R. Lal, and P. F. Reich, "Land degradation: an overview," in Proceedings of the 2nd International Conference on Land Degradation and Desertification, pp. 1-5, Oxford Press, Khon Kaen, Thailand, 2001.

[5] C. den Biggelaar, R. Lal, K. Wiebe, and V. Breneman, "The global impact of soil erosion on productivity. I: absolute and relative erosion-induced yield losses," Advances in Agronomy, vol. 81, pp. 1-48, 2004.

[6] Board on Agriculture, Sustainable Agriculture and the Environment in the Humid Tropics, National Academic Press, 1993.

[7] H. E. Dregne, "Erosion and soil productivity in Africa," Journal of Soil \& Water Conservation, vol. 45, no. 4, pp. 431-436, 1990.

[8] FAO, Land and Environmental Degradation and Desertification in Africa, FAO Corporate Document Repository, 1995.

[9] K. Ikazaki, H. Shinjo, U. Tanaka, S. Tobita, S. Funakawa, and T. Kosaki, "Field-scale aeolian sediment transport in the Sahel, West Africa," Soil Science Society of America Journal, vol. 75, pp. 1885-1897, 2011.

[10] USDA-NRCS, Soil Quality Indicators: Organic Matter, Soil Quality Information Sheet, The National Soil Survey Centre in Co-Operation with the Soil Quality Institute, NRCS and the National Soil Tilth Laboratory, ARS, 1996.

[11] R. Lal, C. den Biggelaar, and K. D. Wiebe, "Measuring on-site and off-site effects of erosion on productivity and environmental quality," in Proceedings of the OECD Expert Meeting on Soil Erosion and Soil Biodiversity Indicators, Rome, Italy, March 2003.

[12] I. E. Esu, Fundamental of Pedology, Stirling-Horden Publishers, Ibadan, Nigeria, 1999.

[13] A. Warren, S. Batterbury, and H. Osbahr, "Soil erosion in the West African Sahel: a review and an application of a "local political ecology" approach in South West Niger," Global Environmental Change, vol. 11, no. 1, pp. 79-95, 2001.

[14] R. Lal, "Erosion-crop productivity relationships for soils of Africa," Soil Science Society of America Journal, vol. 59, no. 3, pp. 661-667, 1995.

[15] G. Ejeta, "African green revolution needn't be a mirage," Science, vol. 327, no. 5967, pp. 831-832, 2010.

[16] S. S. Abe and T. Wakatsuki, "Sawah ecotechnology-a trigger for a rice green revolution in sub-Saharan Africa: basic concept and policy implications," Outlook in Agriculture, vol. 40, no. 3, pp. 221-227, 2011.

[17] Soil Science Society of America, Glossary of Soil Science Terms, American Society of Agronomy, Crop Science Society of America, Soil Science Society of America, Madison, Wis, USA, 2001.

[18] USDA SEA-AR, "Soil erosion effects on soil productivity: a research perspective," Journal of Soil and Water Conservation, vol. 36, no. 2, pp. 82-90, 1981.

[19] R. Lal, "Soil erosion on Alfisols in Western Nigeria. V. The changes in physical properties and the response of crops," Geoderma, vol. 16, no. 5, pp. 419-431, 1976.

[20] M. E. Obi and B. O. Asiegbu, "The physical properties of some eroded soils of southeastern Nigeria," Soil Science, vol. 130, no. 1, pp. 39-48, 1980.

[21] R. Lal, "Soil erosion problems on alfisols in Western Nigeria, VI. Effects of erosion on experimental plots," Geoderma, vol. 25, no. 3-4, pp. 215-230, 1981.
[22] M. E. Obi, "Runoff and soil loss from an oxisol in Southeastern Nigeria under various management practices," Agricultural Water Management, vol. 5, no. 3, pp. 193-203, 1982.

[23] J. S. C. Mbagwu, R. Lal, and T. W. Scott, "Effects of artificial desurfacing on Alfisols and Ultisols in southern Nigeria: II. Changes in soil physical properties," Soil Science Society of America Journal, vol. 48, no. 4, pp. 834-838, 1984.

[24] J. S. C. Mbagwu, "Physico-chemical properties and productivity of an Ultisol in Nigeria as affected by long-term erosion," Pedologie, vol. 38, no. 2, pp. 137-154, 1988.

[25] D. J. Oyedele and P. O. Aina, "A study of soil factors in relation to erosion and yield of maize on a Nigerian soil," Soil and Tillage Research, vol. 48, no. 1-2, pp. 115-125, 1998.

[26] P. I. Våje, B. R. Singh, and R. Lal, "Erosional effects on soil properties and maize yield on a volcanic ash soil in Kilimanjaro region, Tanzania," Journal of Sustainable Agriculture, vol. 12, no. 4, pp. 39-53, 1998.

[27] D. J. Oyedele and P. O. Aina, "Response of soil properties and maize yield to simulated erosion by artificial topsoil removal," Plant and Soil, vol. 284, no. 1-2, pp. 375-384, 2006.

[28] M. A. Anikwe, O. E. Ngwu, C. N. Mbah, C. E. Onoh, and E. E. Ude, "Effect of ground cover by different crops on soil loss and physicochemical properties of an Ultisol in South Eastern Nigeria," Nigerian Journal of Soil Science, vol. 17, pp. 94-97, 2007.

[29] F. K. Salako, P. O. Dada, C. O. Adejuyigbe et al., "Soil strength and maize yield after topsoil removal and application of nutrient amendments on a gravelly Alfisol toposequence," Soil and Tillage Research, vol. 94, no. 1, pp. 21-35, 2007.

[30] J. S. C. Mbagwu and R. Lal, "Effect of bulk density and irrigation frequency on root growth and dry matter yields of corn and cowpeas for three Nigerian topsoil and subsoil profiles," Beitrage zur Tropischen Landwirtschaft und Veterinarmedizin, vol. 23, pp. 277-285, 1985.

[31] F. B. S. Kaihura, I. K. Kullaya, M. Kilasara, J. B. Aune, B. R. Singh, and R. Lal, "Soil quality effects of accelerated erosion and management systems in three eco-regions of Tanzania," Soil and Tillage Research, vol. 53, no. 1, pp. 59-70, 1999.

[32] R. Lal, "Soil erosion on Alfisols in Western Nigeria. IV. Nutrient element losses in runoff and eroded sediments," Geoderma, vol. 16, no. 5, pp. 403-417, 1976.

[33] C. K. K. Gachene, N. Karanja, J. G. Mureithi, P. Khisa, and J. Maina, "Farmers' evaluation of legume cover crops for erosion control in Gathwariga catchment, Kenya," International Journal of Agriculture and Rural Development, vol. 5, pp. 176-186, 2004.

[34] M.G. Wolman, "Soil erosion and crop productivity: a worldwide perspective," in Soil Erosion and Crop Productivity, R. F. Follet and B. A. Stewarts, Eds., pp. 9-21, American Society of Agronomy, Madison, Wis, USA, 1985.

[35] L. D. Meyer, A. Bauer, and R. D. Heil, "Experimental approaches for quantifying the effect of soil erosion on productivity," in Soil Erosion and Crop Productivity, R. F. Follet and B. A. Stewarts, Eds., pp. 213-233, American Society of Agronomy, Madison, Wis, USA, 1985.

[36] J. S. C. Mbagwu, "Soil-loss tolerance of some Nigerian soils in relation to profile characteristics," Turrialba, vol. 41, no. 2, pp. 223-229, 1991.

[37] J. Bouma, N. H. Batjes, and J. J. R. Groot, "Exploring land quality effects on world food supply," Geoderma, vol. 86, no. 1-2, pp. 43-59, 1998. 
[38] R. Lal, "Agronomic impact of soil degradation," in Methodology for Assessment of Soil Degradation, R. Lal, W. Blum, C. Valentine, and B. A. Stewart, Eds., pp. 459-473, CRC Press, Boca Raton, Fla, USA, 1997.

[39] C. A. Igwe, "Tropical soils, physical properties," in Encyclopedia of Agrophysics, J. Glinski, J. Horabik, and J. Lipiec, Eds., pp. 934-937, Springer, 1st edition, 2011.

[40] J. S. C. Mbagwu, R. Lal, and T. W. Scott, "Effects of desurfacing of Alfisols and Ultisols in southern Nigeria: I. Crop performance," Soil Science Society of America Journal, vol. 48, no. 4, pp. 828-833, 1984.

[41] A. I. Adama and C. Quansah, "Cumulative soil loss under different tillage practices and its effects on the growth and yield of maize in the semi-deciduous forest zone of Ghana," in Proceedings of the African Crop Science Conference, vol. 9, pp. 343-349, 2009.

[42] P. O. Aina and E. Egolum, "The effect of cattle feedlot manure and inorganic fertilizer on the improvement of subsoil productivity," Soil Science, vol. 129, no. 4, pp. 212-217, 1980.

[43] M. M. Bakker, G. Govers, and M. D. A. Rounsevell, "The crop productivity-erosion relationship: an analysis based on experimental work," Catena, vol. 57, no. 1, pp. 55-76, 2004.

[44] J. S. C. Mbagwu, "Effects of soil erosion on the productivity of agricultural lands in the humid tropics," Beitrage zur Tropischen Landwirtschaft und Veterinarmedizin, vol. 24, no. 2, pp. 161-175, 1986.

[45] O. E. Ngwu, J. S. C. Mbagwu, and M. E. Obi, "Effects of surface soil loss in southeastern Nigeria: 1 . Crop performance," Nigerian Journal of Soil Research, vol. 6, pp. 1-8, 2005.

[46] G. F. Wilson, R. Lal, and B. N. Okigbo, "Effects of cover crops on soil structure and on yield of subsequent arable crops grown under strip tillage on an eroded alfisol," Soil and Tillage Research, vol. 2, no. 3, pp. 233-250, 1982.

[47] E. Owusu-Sekyere, E. K. Nakashima, and T. Wakatsuki, "Extending cocoa agroforestry into sawah ecosystem in Ghanaian inland valleys," Ghana Journal of Agricultural Science, vol. 43, pp. 37-44, 2010.

[48] S. Hirose and T. Wakatsuki, Restoration of Inland Valley Ecosystems in West Africa, Association of Agriculture and Forestry Statistics, Tokyo, Japan, 2002.

[49] P. N. Windmeijer and W. Andriesse, Eds., Inland Valleys in West Africa. An Agro-ecological Characterization of Ricegrowing Environments, Institute for Land Reclamation and Improvement (ILRI), Wageningen, The Netherlands, 1993.

[50] T. Wakatsuki and T. Masunaga, "Ecological engineering for sustainable food production and the restoration of degraded watersheds in tropics of low $\mathrm{pH}$ soils: focus on West Africa," Soil Science and Plant Nutrition, vol. 51, no. 5, pp. 629-636, 2005.

[51] A. L. Kaswamila and J. A. Mkavidanda, "The neglect of traditional agro-forestry (TAF) and its effects on soil erosion and crop yield: the case of the West Usambara Mountains," in Proceedings of the International Conference on Geo-Information for Sustainable Land Management (SLM '97), pp. 17-21, Enschede, The Netherlands, August 1997.

[52] West Africa Rice Development Association WARDA, Africa Rice Trends, 2007, The Africa Rice Center, Cotonou, Benin, 2008.

[53] S. E. Obalum, J. C. Nwite, J. Oppong, C. A. Igwe, and T. Wakatsuki, "Variations in selected soil physical properties with landforms and slope within an inland valley ecosystem in
Ashanti Region of Ghana," Soil and Water Research, vol. 6, pp. 73-82, 2011.

[54] S. S. Abe, M. M. Buri, R. N. Issaka, P. Kiepe, and T. Wakatsuki, "Soil fertility potential for rice production in West African lowlands," Japan Agricultural Research Quarterly, vol. 44, no. 4, pp. 343-355, 2010.

[55] A. Bationo, A. Hartemink, O. Lungu et al., "African soils: their productivity and profitability of fertilizer use," in Proceedings of the African Fertilizer Summit, Abuja, Nigeria, June 2006.

[56] B. Koné, G. L. Amadji, S. Aliou, S. Diatta, and C. Akakpo, "Nutrient constraint and yield potential of rice on upland soil in the south of the Dahoumey gap of West Africa," Archives of Agronomy and Soil Science, vol. 57, pp. 763-774, 2011.

[57] J. C. Nwite, C. A. Igwe, and T. Wakatsuki, "Evaluation of sawah rice management system in an inland valley in southeastern Nigeria. I: soil chemical properties and rice yield," Paddy and Water Environment, vol. 6, no. 3, pp. 299-307, 2008.

[58] M. M. Buri, R. N. Issaka, and T. Wakatsuki, "Determining optimum rates of mineral fertilizers for economic rice grain yields under the "sawah" system in Ghana," West African Journal of Applied Ecology, vol. 12, 2008. 

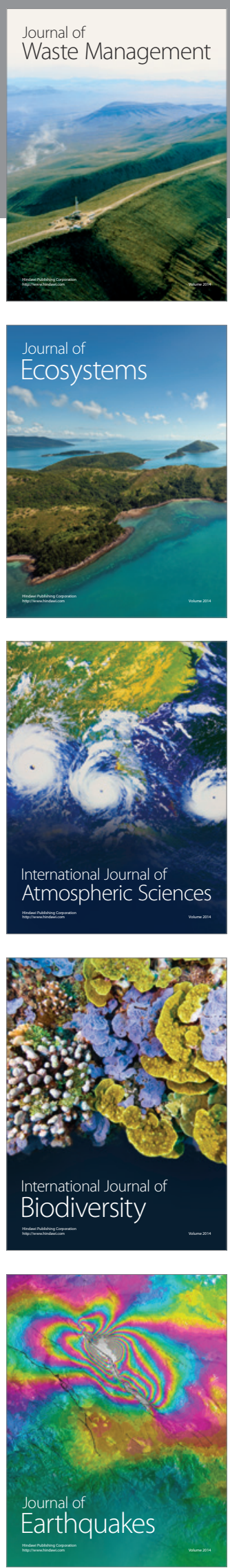
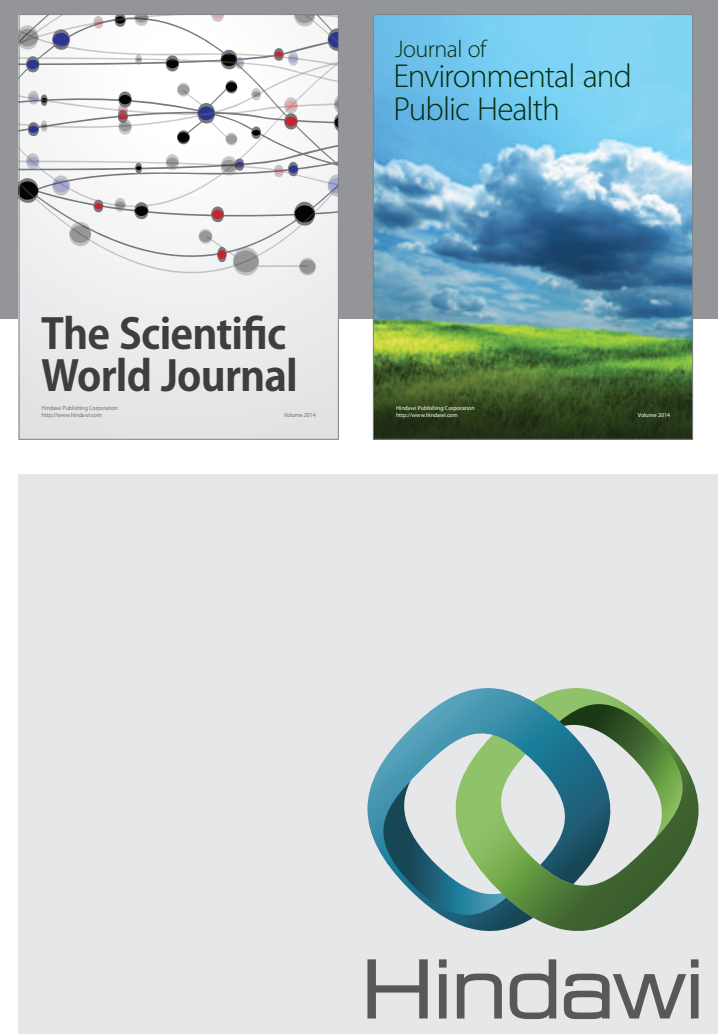

Submit your manuscripts at

http://www.hindawi.com
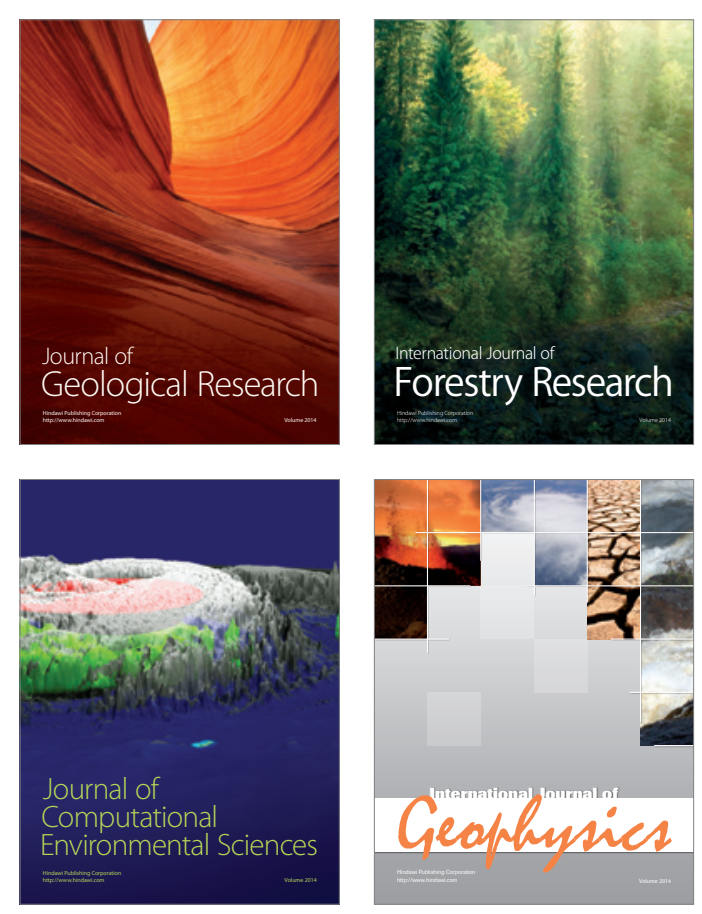
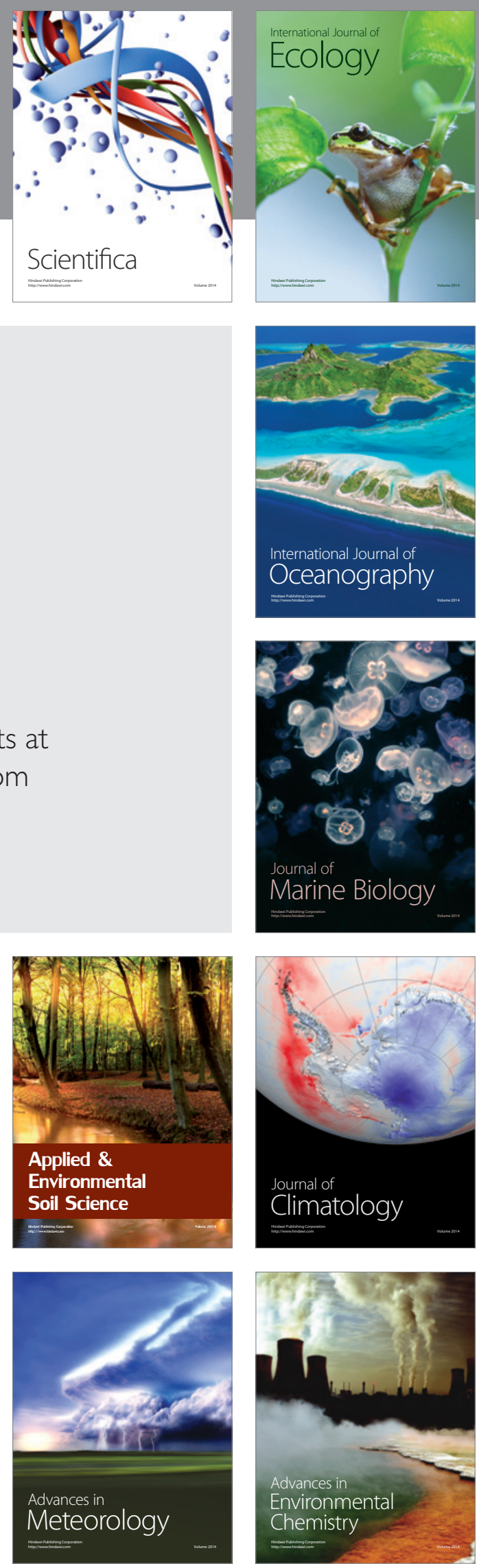